\title{
Decreased peroxynitrite inhibitory activity in induced sputum in patients with bronchial asthma
}

\author{
H Kanazawa, S Shiraishi, K Hirata, J Yoshikawa
}

Thorax 2002;57:509-513

See end of article for authors' affiliations

......................

Correspondence to: Dr H Kanazawa,

Department of Respiratory

Medicine, Graduate

School of Medicine, Osaka

City University, 1-4-3

Asahi-machi, Abenoku,

Osaka, 545-8585, Japan;

kanazawa-h@

med.osaka-cu.ac.jp

Revised version received 26 October 2001

Accepted for publication

10 December 2001

\begin{abstract}
Background: The production of peroxynitrite, an extremely potent oxidant, is increased in inflammatory lung disease. It is therefore important to measure antioxidant activity against peroxynitrite in epithelial lining fluid to examine the physiological effects of peroxynitrite in the airways of patients with asthma. This study was designed to determine whether peroxynitrite inhibitory activity in induced sputum is correlated with clinical characteristics and airway inflammatory indices in asthmatic patients. Methods: Inflammatory indices were measured in induced sputum from 25 patients with asthma and 12 normal control subjects. Peroxynitrite inhibitory activity was also measured by monitoring rhodamine formation in sputum samples.

Results: Peroxynitrite inhibitory activity in induced sputum was significantly lower in asthmatic patients $(52.4(24.5) \%)$ than in normal control subjects $(92.1$ (3.9)\%, p<0.0001). Its activity was significantly correlated with forced expiratory volume in 1 second $\left(\mathrm{FEV}_{1}\right) \%$ predicted $(r=0.774, \mathrm{p}<0.0001)$ and bronchial hyperreactivity to methacholine $(r=0.464, p=0.023)$. There was a significant negative correlation between peroxynitrite inhibitory activity and the degree of eosinophilic airway inflammation $1 \%$ eosinophils, $r=-0.758, p<0.0001$; eosinophil cationic protein, $r=-0.780, p<0.0001)$.

Conclusions: Decreased peroxynitrite inhibitory activity occurs in induced sputum of asthmatic patients. Since even in patients with stable asthma the airway lining fluid lacks peroxynitrite inhibitory activity, large amounts of peroxynitrite, which are further increased during an acute asthma attack, would not be completely inactivated and asthmatic airways might have markedly increased susceptibility to peroxynitrite induced airway injury.
\end{abstract}

$\mathrm{P}$ eroxynitrite is formed by the reaction of nitric oxide (NO) with superoxide anion. ${ }^{1}$ In many pathological conditions, including airway inflammation, simultaneous cellular production of superoxide anion and NO may occur, potentially leading to continuous formation of peroxynitrite. Peroxynitrite is an extremely potent oxidant that can cause lipid peroxidation, DNA damage, and alterations of protein function in vitro. ${ }^{2}$ A previous study has suggested that single administration of peroxynitrite to guinea pig airways induces epithelial damage and hence airway hyperresponsiveness. ${ }^{3}$ Moreover, nitrogen derived oxidants have been shown to be formed in human lung injury, suggesting that peroxynitrite might have an important role in inflammatory lung disease. ${ }^{4}$ However, little is known about the antioxidant activity against peroxynitrite in asthmatic airways. It seems likely that the thin layer of epithelial lining fluid (ELF) may provide antioxidant protection against peroxynitrite and serve as a front line defence for airway epithelial cells. The major antioxidants in ELF are based on thiols which are classified according to their molecular weight. Low molecular weight thiols include glutathione, cysteine, homocysteine, albumin, and $\mathrm{N}$-acetylcysteine; high molecular weight thiols include penicillamine. ${ }^{5}$ Thus, various kinds of thiols in ELF may function as antioxidants against peroxynitrite in the respiratory tract. We have therefore measured total antioxidant activity against peroxynitrite in ELF to examine the physiological effects of peroxynitrite in asthmatic airways. The study was designed to determine whether peroxynitrite inhibitory activity in induced sputum is correlated with clinical characteristics and airway inflammatory indices in asthmatic patients.

\section{METHODS}

\section{Subjects}

Twenty five asthmatic patients of mean age 39.8 years and mean forced expiratory volume in 1 second $\left(\mathrm{FEV}_{1}\right)$ 90.7\% diagnosed according to the American Thoracic Society criteria for asthma ${ }^{6}$ and 12 normal controls of mean age 31.8 years and mean $\mathrm{FEV}_{1} 115.7 \%$ participated in the study. The control subjects were healthy lifelong non-smoking volunteers who had no history of lung disease and all the patients were nonsmokers. Their clinical characteristics are shown in table 1.

Methacholine inhalation challenge testing was performed on the asthmatic patients. The challenge tests were performed at 13.00 hours to eliminate the effects of diurnal variation. Following baseline spirometric tests and inhalation of diluent to establish the stability of $\mathrm{FEV}_{1}$, the subjects were instructed to take slow inspirations in each set of inhalations. All patients had bronchial hyperreactivity to methacholine. Their regular medication consisted of $\beta_{2}$ agonists and theophylline, and none were receiving oral or inhaled corticosteroids. Medications were not changed for 1 month before the study and were withdrawn for at least 12 hours before the methacholine challenge test and sputum induction. The patients were all clinically stable and none had a history of respiratory infection during at least the 4 weeks preceding the study.

All subjects gave their written informed consent for participation in the study which was approved by the ethics committee of Osaka City University.

\section{Sputum induction and processing}

Sputum induction was performed three days after the methacholine challenge test. Spirometric tests were performed before inhalation of $200 \mu \mathrm{g}$ salbutamol via a metered dose inhaler. All subjects were instructed to wash their mouth thoroughly with water. They then inhaled 3\% saline at room temperature, nebulised by an ultrasonic nebuliser (NE-U12, Omron Co, Tokyo, Japan) at maximum output. They were encouraged to cough deeply at 3 minute intervals thereafter. After sputum induction the spirometric tests were repeated. If the $\mathrm{FEV}_{1}$ fell, the subjects were required to wait until it 
Table 1 Clinical characteristics of study subjects

\begin{tabular}{|c|c|c|}
\hline & Asthmatic patients $(n=25)$ & Normal controls $(n=12)$ \\
\hline$M: F$ & 14:11 & $7: 5$ \\
\hline Age (years) & $39.8(20-59)^{*}$ & $31.8(24-40)$ \\
\hline $\mathrm{FEV}_{1}(\%)$ & $90.7(75-115)^{* *}$ & 115.7 (105-127) \\
\hline $\mathrm{PC}_{20}$ methacholine $(\mu \mathrm{g} / \mathrm{ml}) \dagger$ & $3.28(2.80-3.96)$ & ND \\
\hline \multicolumn{3}{|l|}{ Sputum } \\
\hline Eosinophils (\%) & $15.6(1.0-32.0)^{* *}$ & $0.78(0.1-1.5)$ \\
\hline $\mathrm{ECP}(\mathrm{ng} / \mathrm{ml})$ & $699.6(90-1400)^{* *}$ & $118.3(50-180)$ \\
\hline \multicolumn{3}{|c|}{$\begin{array}{l}\text { Values are mean (range). } \\
\mathrm{FEV} \mathrm{V}_{1}=\text { forced expiratory volume in } 1 \text { second; } \mathrm{PC}_{20}=\text { concentration of methacholine causing a } 20 \% \text { fall in } \mathrm{FEV}_{1} \\
\mathrm{ND}=\text { not determined. } \\
{ }^{*} \mathrm{p}<0.05,{ }^{*} \mathrm{p}<0.01 \text { asthmatic patients } v \text { normal controls. } \\
\dagger \text { Geometric mean. }\end{array}$} \\
\hline
\end{tabular}

returned to baseline value. The sputum sample diluted with phosphate buffer solution (PBS) containing dithiothreitol (DTT, final concentration $1 \mathrm{mmol} / \mathrm{l}$ ) was then centrifuged at $400 \mathrm{~g}$ for 10 minutes and the cell pellet was resuspended. Total cell counts were performed with a haemocytometer and slides were made using a cytospin (Cytospin 3; Shandon, Tokyo, Japan) and stained with May-Grunwald-Giemsa stain for differential cell counts. The supernatant was stored at $-70^{\circ} \mathrm{C}$ for subsequent assay for eosinophil cationic protein (ECP). The ECP concentration was measured using a radioimmunoassay kit (Pharmacia Diagnostics, Uppsala, Sweden). The sol phase of the sputum was used for measurement of peroxynitrite inhibitory activity, avoiding the potential confounding influence of DTT. ${ }^{7}$ The sol phase was obtained by ultracentrifuging the remaining portion of the sputum sample at $60000 \mathrm{~g}$ for 60 minutes at $4^{\circ} \mathrm{C}$; this was stored at $-70^{\circ} \mathrm{C}$ for subsequent assay for peroxynitrite inhibitory activity. All subjects produced an adequate specimen of sputum of at least $2 \mathrm{ml}$ which, on differential cell counting, contained $<10 \%$ squamous cells.

\section{Measurement of peroxynitrite inhibitory activity}

Working solutions of peroxynitrite (Wako Pure Chemical Industries Ltd, Osaka Japan) were prepared by dilution in $0.1 \mathrm{~N} \mathrm{NaOH}$ just before use as $10^{-2} \mathrm{~mol} / \mathrm{l}$ solutions, and further dilutions were made in PBS. The peroxynitrite concentration was determined spectrophotometrically by measuring the absorption at $302 \mathrm{~nm}\left(\mathrm{eM}=1670 \mathrm{M}^{-1} \mathrm{~cm}^{-1}\right)$. Peroxynitrite readily oxidises dihydrorhodamine-123 whereas superoxide anion, $\mathrm{H}_{2} \mathrm{O}_{2}$, and NO alone do not. ${ }^{8}$ A standard curve of oxidising activity of dihydrorhodamine-123 to rhodamine was constructed with peroxynitrite. Peroxynitrite inhibitory activity was assayed by monitoring rhodamine formation at $500 \mathrm{~nm}$ in reaction mixtures containing $200 \mu \mathrm{l}$ sputum, $1.3 \mathrm{ml}$ dihydrorhodamine-123 diluted with PBS (pH 7.4), and $500 \mu \mathrm{l}$

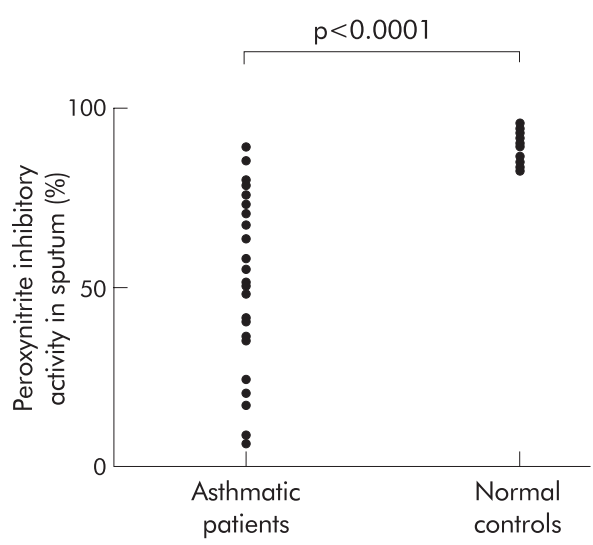

Figure 1 Peroxynitrite inhibitory activity in induced sputum in asthmatic patients and normal controls. peroxynitrite for 30 minutes at $37^{\circ} \mathrm{C}$. Peroxynitrite inhibitory activity was assayed in at least triplicate and reproducibility of the assay was confirmed by repeat measurements in the same subjects on separate days. A recent study supports the specificity of this assay system for peroxynitrite.

\section{Statistical analysis}

All values are presented as mean (SD). The Mann-Whitney U test was used for intergroup comparisons and the significance of correlations was evaluated by determining Spearman rank correlation coefficients. A p value of less than 0.05 was considered significant.

\section{RESULTS}

Baseline lung function and bronchial hyperreactivity to methacholine in the 25 asthmatic patients are shown in table 1. The percentage of eosinophils and concentration of ECP in induced sputum were significantly higher in asthmatic patients (\% eosinophils 15.6 (9.1)\%, p<0.0001; ECP 699.6 (408.9) ng/ml, p<0.0001) than in control subjects (\% eosinophils 0.78 (0.50)\%; ECP 118.3 (40) ng/ml).

Peroxynitrite inhibitory activity in induced sputum was significantly lower in asthmatic patients than in control subjects (asthmatics 52.4 (24.5)\%, normal controls 92.1 (3.9)\%, p <0.0001; fig l) and was significantly correlated with FEV $1 \%$ predicted $(r=0.774, \mathrm{p}<0.0001$; fig 2$)$ and bronchial hyperreactivity to methacholine $(r=0.464, \mathrm{p}=0.023$; fig 3$)$. Moreover, there was a significant negative correlation between peroxynitrite inhibitory activity and the degree of eosinophilic airway inflammation (\% eosinophils: $r=-0.758, \mathrm{p}<0.0001$; ECP: $r=-0.780, p<0.0001$; fig 4 ).

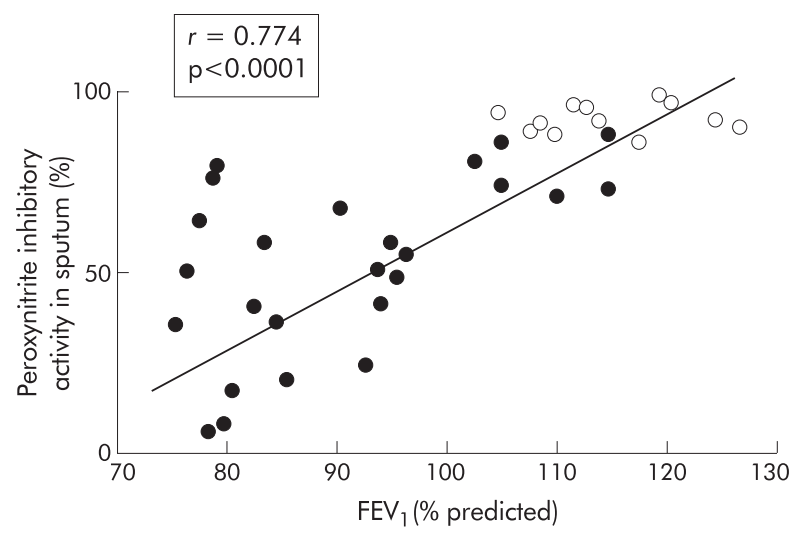

Figure 2 Correlation between peroxynitrite inhibitory activity in induced sputum and FEV $(\%$ predicted). 0 , normal controls; $\bullet$, asthmatic patients. 


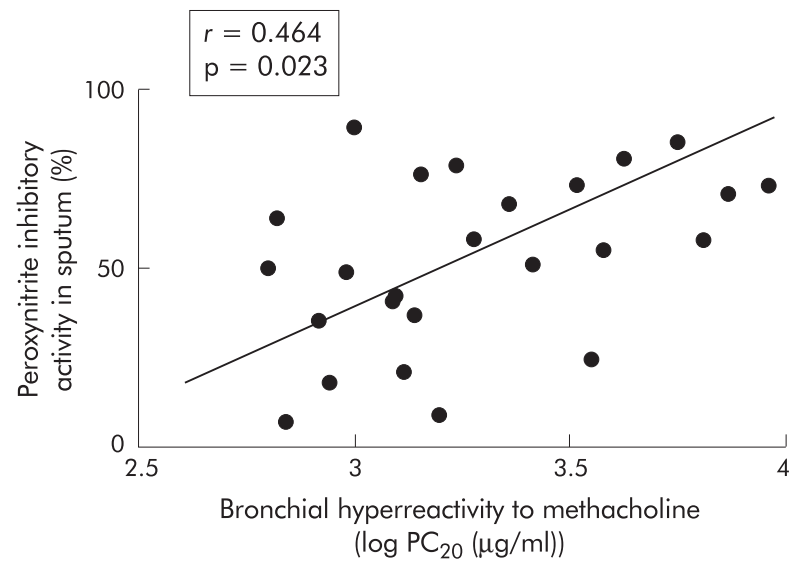

Figure 3 Correlation between peroxynitrite inhibitory activity in induced sputum and bronchial hyperreactivity to methacholine.
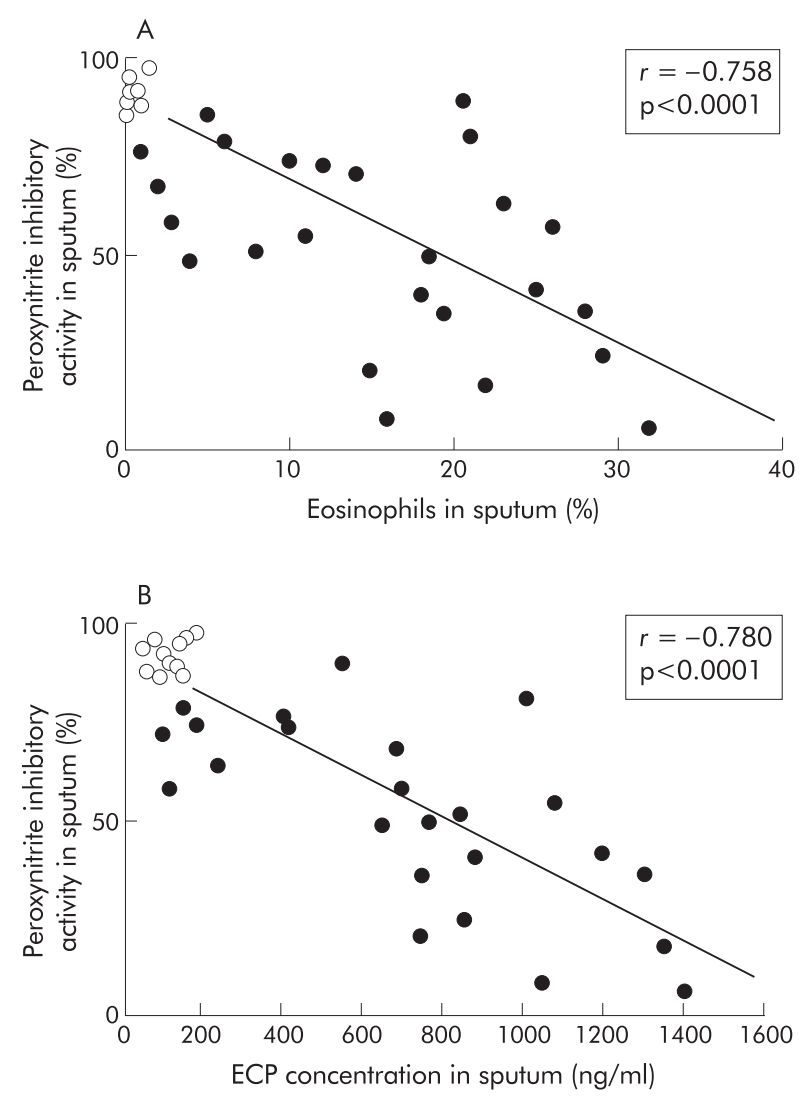

Figure 4 Correlation between peroxynitrite inhibitory activity in induced sputum and (A) percentage eosinophils and (B) ECP concentration in induced sputum. O normal controls; $\bullet$, asthmatic patients.

\section{DISCUSSION}

In this study peroxynitrite inhibitory activity was assayed by monitoring rhodamine formation since the oxidation of dihydrorhodamine- 123 to rhodamine is mediated by peroxynitrite and not by either NO or superoxide anion alone. Using this method, we found that peroxynitrite inhibitory activity in induced sputum was significantly lower in asthmatic patients than in normal controls, and that its activity was correlated with the degree of airway obstruction and airway hyperreactivity to methacholine. We also found a significant negative correlation between peroxynitrite inhibitory activity in induced sputum and the degree of eosinophilic airway inflammation.
The airways of asthmatic patients are often inflamed and it has been shown that the production of superoxide anion by airway inflammatory cells is increased. ${ }^{10}$ The concentration of NO in exhaled air of asthmatic patients is also increased, ${ }^{11}$ and we have previously found a higher concentration of NO derivatives in induced sputum of patients with asthma. ${ }^{12}$ From the existing evidence it is likely that peroxynitrite is formed in the respiratory tract. However, the cellular source of peroxynitrite in asthmatic airways is unclear. Previous studies have reported that the production of peroxynitrite is increased in airway epithelial cells and eosinophils in asthmatic patients compared with normal control subjects. ${ }^{13}{ }^{14}$ It is possible that decreased peroxynitrite inhibitory activity is likely to reflect the increases in reactive oxygen and nitrogen intermediates in asthmatic airway fluid. However, we did not measure peroxynitrite or nitric oxide levels in the airways of our asthmatic patients, nor did we determine peroxynitrite inhibitory factors in induced sputum as we did not directly measure the levels of airway thiols such as glutathione, cysteine, and albumin. In future studies we plan to measure the levels of peroxynitrite and airway thiols directly.

Barnes $^{15}$ has suggested that peroxynitrite may indirectly exacerbate the airway inflammatory response by inducing the shedding of airway epithelial cells-which may occur even in patients with mild asthma-thereby exposing afferent nerve endings. This might induce the release of sensory neuropeptides through axon reflexes and result in bronchoconstriction, mucus hypersecretion, and microvascular leakage leading to oedema of the airway wall and extravasation of plasma into the airway lumen. ${ }^{16}$ We have also previously reported that peroxynitrite altered $\beta_{2}$ aderenoceptor function ${ }^{17}$ and inactivated neutral endopeptidase in the airways. ${ }^{18}$ An imbalance of peroxynitrite stress/antioxidant defence may therefore contribute to the pathogenesis of bronchial asthma. The reaction of peroxynitrite with airway thiols is associated with their oxidation to the corresponding disulfide. Our method would evaluate the reduced form antioxidant activity against peroxynitrite. A previous study found that asthmatic patients have increased levels of total glutathione (oxidised plus reduced forms) in bronchoalveolar lavage fluid. ${ }^{19}$ However, it is important to emphasise that local antioxidant defences in asthmatic patients are mediated only by reduced antioxidants. It seems likely that a balance exists between peroxynitrite generation and antioxidant defences to maintain normal airway function. When the balance is shifted towards increased peroxynitrite generation, the reduced antioxidants are diminished and therefore the asthmatic airways have markedly increased susceptibility to peroxynitrite.

In conclusion, we have found decreased peroxynitrite inhibitory activity in the airway lining fluid of asthmatic patients. Since ELF lacks peroxynitrite inhibitory activity, even in patients with stable asthma, large amounts of peroxynitrite would not be completely inactivated, even in an acute asthma attack, and the asthmatic airway might markedly increase the susceptibility to peroxynitrite induced airway injury.

\section{ACKNOWLEDGEMENT}

This work was supported by grant-in-aid for Scientific Research (13670611) from the Ministry of Education, Science and Culture, Japan.

\section{Authors' affiliations}

H Kanazawa, S Shiraishi, K Hirata, J Yoshikawa, Department of

Respiratory Medicine, Graduate School of Medicine, Osaka City

University, 1-4-3 Asahi-machi, Abenoku, Osaka, 545-8585, Japan

\section{REFERENCES}

1 Beckman JS, Beckman TW, Chen J, et al. Apparent hydroxyl radical production by peroxynitrite: implication for endothelial injury from nitric oxide and superoxide. Proc Natl Acad Sci USA 1990;87:1620-4. 
2 Beckman JS. Reactions between nitric oxide, superoxide, and peroxynitrite: footprints of peroxynitrite in vivo. Adv Pharmacol 1995;34:17-43.

3 Sadeghi-Hashijn G, Folkerts G, Henricks PA, et al. Peroxynitrite induces airway hyperresponsiveness in guinea pigs in vitro and in vivo. Am J Respir Crit Care Med 1996;153:1697-701.

4 Kooy NW, Royall JA, Ye YZ, et al. Evidence for in vivo peroxynitrite production in human acute lung injury. Am J Respir Crit Care Med 1995;151:1250-4

5 Cantin AM, Fells GA, Hubbard RC, et al. Antioxidant macromolecules in the epithelial lining fluid of the normal human lower respiratory tract. $J$ Clin Invest 1990;86:962-71.

6 American Thoracic Society. Standards for the diagnosis and care of patients with chronic obstructive pulmonary disease (COPD) and asthma. Am Rev Respir Dis 1987:136:225-44.

7 Keatings VM, Collins PD, Scott DM, et al. Differences in interleukin-8 and tumor necrosis factor- $\alpha$ in induced sputum from patients with chronic obstructive pulmonary disease or asthma. Am J Respir Crit Care Med 1996; 153:530-4.

8 Crow JP, Beckman JS, McCord JM. Sensitivity of the essential zinc-thiolate moiety of yeast alchol dehydrogenase to hypochlorite and peroxynitrite. Biochemistry 1995;34:3544-52.

9 Kanazawa H, Hirata K, Yoshikawa J. Possible mechanism of bronchoconstriction by SIN-1 in anaesthetized guinea pigs: roles of nitric oxide and peroxynitrite. Clin Exp Allergy 2000;30:445-50.

10 Calhoun WJ, Reed HE, Moest DR, et al. Enhanced superoxide production by alveolar macrophages and air space cells, airway inflammation, and alveolar macrophage density changes after segmental antigen bronchoprovocation in allergic subjects. Am Rev Respir Dis 1992; 145:317-25.

11 Kharitonov SA, Yates D, Robins RA, et al. Increased nitric oxide in exhaled air of asthmatic patients. Lancet 1994;343:133-5.

12 Kanazawa H, Shoji S, Yamada M, et al. Increased levels of nitric oxide derivatives in induced sputum in patients with bronchial asthma. J Allergy Clin Immunol 1997:99:624-9.

13 Saleh D, Ernst P, Lim S, et al. Increased formation of the potent oxidant peroxynitrite in the airways of asthmatic patients is associated with induction of nitric oxide synthase: effect of inhaled glucocorticoid. FASEB J 1998;12:929-37.

14 Ichinose M, Sugiura H, Yamagata S, et al. Increase in reactive nitrogen species production in chronic obstructive pulmonary disease airways. Am J Respir Crit Care Med 2000;162:701-6.

15 Barnes PJ. NO or no NO in asthma? Thorax 1996;51:218-20.

16 Barnes PJ. Asthma as an axon reflex. Lancet 1986;i:242-5.

17 Kanazawa H, Shiraishi S, Okamoto T, et al. Inhibition of bronchoproective effects of $\beta_{2}$-adrenoceptor agonists by peroxynitrite in guinea pig airways. Am J Respir Crit Care Med 1999:159:1272-6.

18 Kanazawa H, Hirata K, Yoshikawa J. Administration of SIN-1 induces guinea pig airway hyperresponsiveness through inactivation of airway neutral endopeptidase. Int Arch Allergy Immunol 1999;120:317-22.

19 Smith LJ, Houston M, Anderson J. Increased levels of glutathione in bronchoalveolar lavage fluid from patients with asthma. Am Rev Respir Dis 1993;147:1461-4

\section{Clinical Evidence-Call for contributors}

Clinical Evidence is a regularly updated evidence based journal available world wide both as a paper version and on the internet. Clinical Evidence urgently needs to recruit a number of new contributors. Contributors are health care professionals or epidemiologists with experience in evidence based medicine and the ability to write in a concise and structured way.

We are presently interested in finding contributors with an interest in the following clinical areas:

$\begin{array}{ll}\text { Acute bronchitis } & \text { Hepatitis B } \\ \text { Acute sinusitis } & \text { Hepatitis C } \\ \text { Cataract } & \text { HIV } \\ \text { Genital warts } & \end{array}$

Being a contributor involves:

- Appraising the results of literature searches (performed by our Information Specialists) to identify high quality evidence for inclusion in the journal.

- Writing to a highly structured template (about 1500-3000 words), using evidence from selected studies, within 6-8 weeks of receiving the literature search results.

- Working with Clinical Evidence Editors to ensure that the text meets rigorous epidemiological and style standards.

- Updating the text every eight months to incorporate new evidence.

- Expanding the topic to include new questions once every 12-18 months.

If you would like to become a contributor for Clinical Evidence or require more information about what this involves please send your contact details and a copy of your CV, clearly stating the clinical area you are interested in, to Polly Brown (pbrown@bmigroup.com). 